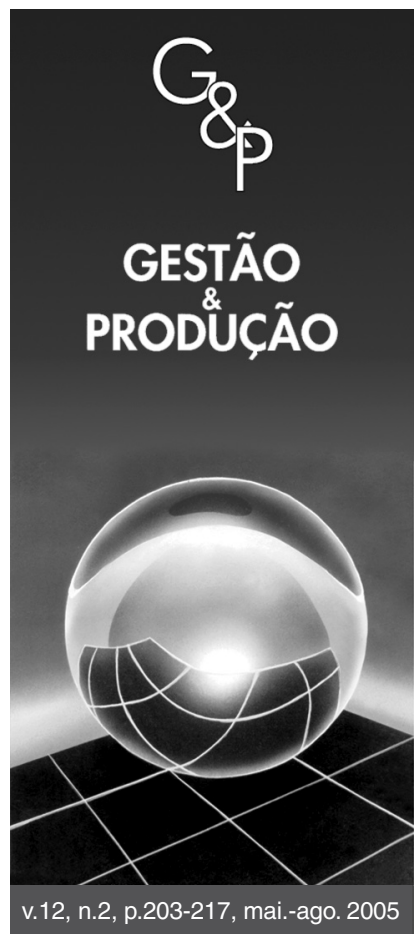

\title{
OTIMIZAÇÃO NO DIMENSIONAMENTO E SEQÜENCIAMENTO DE LOTES DE PRODUÇÃO: ESTUDO DE CASO NUMA FÁBRICA DE RAÇÕES
}

\author{
Eli Angela Vitor Toso \\ Reinaldo Morabito
}

Departamento de Engenharia de Produção, Universidade Federal de São Carlos, CEP 13565-905, São Carlos, SP, e-mail: eli@dep.ufscar.br, morabito@ power.ufscar.br

Resumo

Neste trabalho, é proposta uma abordagem para otimizar o problema integrado de dimensionamento e seqüenciamento de lotes de produção em uma empresa do setor de nutrição animal. Tal problema consiste em decidir quanto produzir de cada produto em cada período, considerando a seqüencia de produção dos lotes, de maneira a satisfazer a demanda e minimizar os custos de produção e estoques. Uma das grandes dificuldades para a programação da produção na empresa é integrar estas decisões, uma vez que os tempos de preparação (setup) são bem dependentes da seqüência produtiva. O problema é modelado por programação linear inteira mista e resolvido por meio da linguagem de modelagem GAMS/CPLEX com alguns procedimentos para reduzir os tempos computacionais. Experimentos realizados com dados reais mostram que esta abordagem é capaz de gerar resultados melhores do que os utilizados pela empresa.

Palavras-chave: dimensionamento de lotes, seqüenciamento da produção, tempo de preparação dependente da seqüência, nutrição animal.

\section{Introdução}

Apesar de estar sofrendo com a globalização dos mercados e com a conjuntura econômica e política nacional, a indústria brasileira de nutrição animal tem crescido nos últimos anos, por exemplo, em 2002 cresceu 7,17\%, com um faturamento de mais de US\$ 7 bilhões (SINDIRAÇÕES, 2003; ANFAL, 2003). A presença de grandes grupos nacionais e multinacionais tem acirrado a competitividade, forçando as empresas a uma busca contínua por melhores desempenhos operacionais. Neste contexto, a área de Planejamento e Controle da Produção (PCP) exerce um papel importante.

Num escopo de curto a médio prazo, a tomada de decisões no PCP envolve questões como o dimensionamento, seqüenciamento e programação de lotes de produção. Estas questões são especialmente complicadas para esta indústria devido a algumas peculiaridades, como a alta sazonalidade dos produtos e os tempos de preparação (setup) do processo produtivo dependentes da sequiência. De forma geral, o problema de dimensionamento de lotes (lot sizing) consiste em determinar o que e quanto produzir, ajustando a capacidade produtiva às variações de demanda. Para tanto, dispõe de duas alternativas viáveis: aumento da capacidade (por exemplo, com a utilização de horas extras) e antecipação da produção nos períodos de folga (utilização de estoques). O problema de seqüenciamento e de programação de lotes (sequencing and scheduling) consiste em determinar em que ordem produzir os lotes de forma a minimizar os tempos de preparação, que diminuem a capacidade produtiva (Johnson e Montgomery, 1974; Hax e Candea, 1984; Graves et al., 1993; Gershwin, 1994; Nahmias, 1995).

Estas decisões do PCP são freqüentemente tratadas de forma independente, tanto na literatura quanto na prática (Drexl e Kimms, 1997; Karimi et al., 2003). O seqüen- 
ciamento e a programação dos lotes de produção geralmente são uma tarefa posterior ao dimensionamento dos lotes, atribuída ao chão-de-fábrica. Na indústria de nutrição animal (assim como em outros processos similares, como a produção de refrigerantes; Toledo et al., 2002, Rangel e Ferreira, 2003), tratar estes problemas independentemente, gera dificuldades para tornar a produção flexível às mudanças do mercado e para obter soluções (para os tamanhos e sequiência de lotes) viáveis do ponto de vista da capacidade disponível e do atendimento dos prazos de entrega. Desta forma, um dos desafios do PCP é coordenar de forma eficaz estas decisões. Vale ressaltar que nesta indústria a programação dos lotes (scheduling) num período (p.e., uma semana) é definida apenas pelo seqüenciamento destes lotes (sequencing) neste período. Assim, as decisões de dimensionamento e seqüenciamento de lotes definem o programa de produção.

Neste trabalho, é proposta uma abordagem para otimizar o problema integrado, utilizando um modelo de programação matemática para representar as decisões envolvidas. A abordagem é baseada num estudo de caso de uma empresa localizada no interior de São Paulo, mas também se aplica a outras empresas do setor. O artigo está organizado da seguinte maneira: na seção 2 é feita uma breve descrição da indústria de nutrição animal, com base no estudo de caso realizado. A seção 3 apresenta um modelo de programação linear inteira mista para representar o problema de dimensionamento e seqüenciamento de lotes. Para resolvê-lo, utiliza-se a linguagem de modelagem GAMS (com o solver (PLEX) junto com alguns procedimentos para tentar reduzir os tempos computacionais. Na seção 4 são apresentados os resultados obtidos a partir de alguns experimentos com dados reais, bem como a comparação com os resultados praticados pela empresa. Finalmente, a seção 5 discute conclusões e perspectivas para pesquisa futura.

\section{Descrição do problema}

A indústria de processamento de rações para nutrição animal, como toda agroindústria, tem algumas peculiaridades que podem influenciar a tomada de decisões do PCP. A sazonalidade na demanda por produtos acarreta tanto variações na quantidade produzida quanto variações no mix de produtos. Além disso, a sazonalidade na oferta de matérias-primas (períodos de entressafra) resulta em variações nos seus custos, forçando uma constante reformulação dos produtos para minimizar custos (problema da mistura - blending problem). As empresas do setor têm dificuldades para ajustar suas capacidades produtivas às variações de demanda, alternando períodos (meses) em que a produção é para gerar estoques para demandas futuras (make-to-stock), com períodos de pico em que a alternativa é recorrer a horas extras, o que também eleva os custos operacionais.
Outra característica desta indústria é a perecibilidade dos produtos, que impõe uma importante restrição à programação da produção: os tamanhos dos lotes (principalmente para produtos sob encomenda) não devem exceder a demanda, sob o risco de permanecerem em estoque e ultrapassarem o tempo máximo de armazenamento.

De forma geral, a indústria de nutrição animal pode ser subdividida em: rações comerciais e 'linha pet'. A primeira está voltada para os grandes criadores, enquanto que a segunda tem seus produtos para animais de estimação. Esta indústria, principalmente a linha de rações comerciais, está no começo da cadeia produtiva, fornecendo para grandes e pequenos produtores, alguns ligados a grandes grupos alimentícios. Isto implica em grandes pressões por preços, obrigando o setor a uma racionalização dos custos produtivos, além da exigência do mercado por altos níveis de serviço. Como não há muita diferenciação nos produtos em relação à concorrência, em geral não são tolerados pedidos atrasados (backorders), o que comprometeria a fidelidade dos clientes.

\subsection{0 processo produtivo}

Conforme mencionado, este trabalho está baseado no estudo de caso da unidade produtora de suplementos de uma empresa do setor. Esta planta produz suplementos vitamínicos: sais minerais, núcleos, premixes e promotores para bovinos, eqüinos, suínos e aves, além de alguns produtos para animais de estimação (linha pet). A combinação destes produtos com os animais aos quais são destinados resulta em famílias comerciais, por exemplo: núcleos suínos, núcleos aves ou premix aves.

A primeira etapa do processo produtivo é a dosagem das matérias-primas, que é feita mediante formulação pré-estabelecida pelo departamento técnico. Nesta etapa, o operador programa o sistema, seleciona o produto desejado e o número de bateladas. Automaticamente as válvulas dos silos liberam as matérias-primas que são pesadas separadamente por duas balanças (Figura 1). Parte da formulação (ingredientes que são adicionados em menor quantidade) fica armazenada em bags ou sacos, e são pesados e adicionados manualmente na base do misturador (indicado pelas setas da Figura 1). Conforme vão sendo dosados, os ingredientes são encaminhados para a pré-mistura, e aguardam até que toda a formulação seja pesada.

A próxima etapa é a mistura dos ingredientes que ocorre em três fases: a mistura a seco, a adição de líquidos e uma nova fase de mistura. Terminado este processo a mistura é descarregada no pós-misturador e encaminhada para o ensaque (Figura 1). Os tempos de processamento de cada fase de mistura dependem do tipo de produto. Por exemplo, alguns aditivos e corantes são os mais demorados (cerca de 40 minutos), enquanto que os núcleos e sais minerais demandam o menor tempo de mistura (em torno de 12 minutos). 


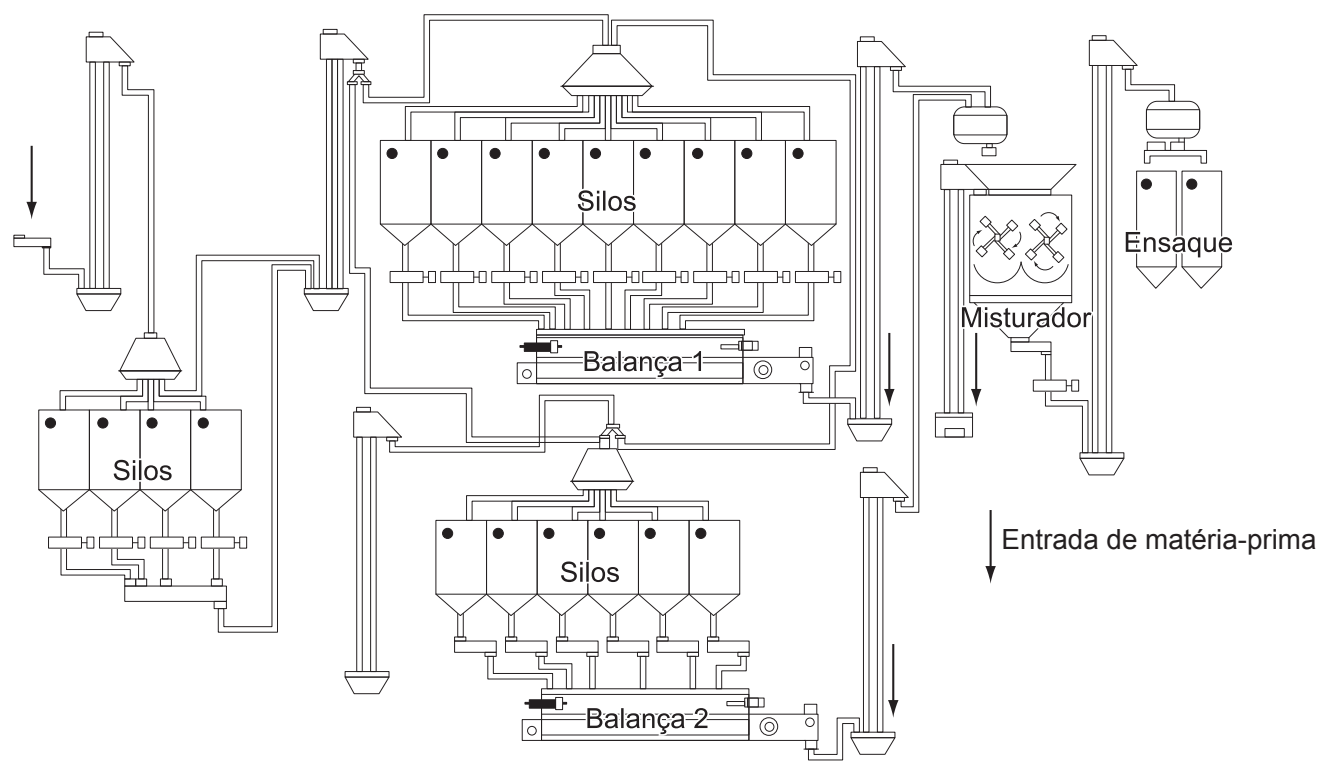

Figura 1. Tela sinótica do processo de fabricação da unidade de suplementos.

O processo de produção é intermitente e ocorre em bateladas, que se referem ao lote mínimo produzido em cada operação. A quantidade produzida em cada batelada de produção é limitada pelo tamanho do misturador, aproximadamente 2000 litros. A medida em quilogramas depende da densidade de cada produto. Do ponto de vista técnico, a quantidade mínima produzida deve ser a metade do volume do misturador, para que ocorra uma homogeneização eficiente. Do ponto de vista econômico, o tempo e os custos envolvidos na produção, estando o misturador completamente cheio ou não, são praticamente os mesmos. Portanto, é pouco viável produzir apenas metade da capacidade volumétrica do misturador. Além disso, a formulação impressa nas ordens de fabricação é balanceada por batelada, e dividir as quantidades durante a fase operacional aumenta a probabilidade de erros. Quando a demanda pelo produto é pequena em relação ao tamanho do misturador, a empresa utiliza uma outra unidade produtiva.

Embora o processo produtivo tenha várias etapas, pode-se considerá-lo monoestágio, pois as etapas produtivas estão dispostas de forma linear, o padrão de fluxo de uma batelada é contínuo e basicamente não existe estoque em processo. Além do mais, toda linha de produção pode ser simplificada como uma máquina na qual entram as matérias-primas e saem os produtos finais, considerando-se o tempo total de produção. Isto facilita a modelagem matemática e a resolução do problema. O misturador é o gargalo da produção, ou seja, a capacidade produtiva depende do tempo de processamento da mistura.

\subsection{Planejamento da produção}

A sazonalidade dos produtos faz com que a demanda varie muito entre os períodos do ano, tanto em relação às quantidades demandadas quanto em relação ao mix de produtos, ocorrendo picos na demanda em determinados períodos do ano. Para ajustar a capacidade produtiva às oscilações na demanda, a empresa adota as seguintes estratégias: com base em previsões e históricos, a empresa varia o nível da força de trabalho por meio de demissão, contratação e treinamento de funcionários, e utiliza horas extras nos meses de pico ao invés de carregar estoques de um mês para outro, devido ao risco relacionado à perecibilidade dos produtos.

Estas decisões estabelecem a capacidade disponível para a produção em cada mês (que varia de acordo com o número de funcionários) e a disponibilidade de utilização de horas extras. Cabe salientar que estas decisões precedem as decisões de dimensionamento e seqüenciamento de lotes. Para o dimensionamento de lotes, o departamento comercial primeiramente realiza uma pesquisa de campo, que resulta em um programa mensal de necessidades dos clientes. Este programa é desdobrado semanalmente pelos departamentos comercial e de PCP, resultando em uma previsão semanal.

Com este desdobramento semanal tem-se uma previsão de demanda inicial, que serve como ponto de partida para a programação da produção de cada semana. Portanto, para determinar o que será produzido na primeira semana do mês, o programador considera a previsão inicial de demanda (para aquela semana do mês) e 
eventuais pedidos extras ou cancelamentos que recebe do departamento comercial. Também considera o saldo disponível ou estoque inicial, o histórico de vendas de cada produto, e eventuais particularidades relativas a determinados clientes da curva $\mathrm{ABC}$, cujos volumes de compra são maiores que a média. Desta forma, a cada semana as previsões de demanda são reavaliadas para determinar o que será produzido dentro de um mês fixo (note que não é utilizado o conceito de horizonte rolante).

De acordo com o histórico de vendas da empresa, a previsão mensal das necessidades dos clientes geralmente se confirma. Entretanto, é difícil prever como será a distribuição da demanda ao longo do mês, ou seja, alguns clientes compram produtos semanalmente, enquanto outros podem fazer seus pedidos na primeira ou na última semana, por exemplo. Desta forma, uma dificuldade do PCP é elaborar um programa de produção que atenda completamente à demanda semanal, não ultrapassando os limites de capacidade disponível, com as alternativas de utilizar horas extras ou carregar estoques de uma semana para outra.

A previsão da demanda mensal, o desdobramento semanal e a programação de cada semana determinam os tamanhos de lote. O próximo passo é verificar os limites da capacidade produtiva, considerando-se também a possível utilização de horas extras. Se existe capacidade disponível para os tamanhos de lote definidos, são emitidas ordens de fabricação para as unidades produtivas, que por sua vez definem o seqüenciamento da produção. O seqüenciamento durante a semana é realizado pelo supervisor de produção, por meio das ordens de fabricação (fornecidas pelo PCP) e verificação de estoque (contagem diária).

Como algumas formulações misturam diversos tipos de medicamentos e minerais, é necessário seqüenciar os lotes de forma a evitar que produtos com agentes contaminantes deixem resíduos na linha de produção (contaminação cruzada ou residual) que comprometam a qualidade do próximo lote. O departamento técnico classifica os produtos por grupos de contaminação e gera uma tabela com as relações de precedência para evitar contaminação. Estas restrições à sequiência produtiva são informadas aos supervisores de produção por meio das ordens de fabricação. Portanto, ao montar a seqüência de produção, eles deverão estar atentos a estas informações.

Para evitar a contaminação cruzada, há duas alternativas: procurar uma sequiência em que nenhum produto contamine os demais ou, quando isso não é possível, fazer uma limpeza química nos equipamentos, o que resulta em um tempo de preparação adicional. O tempo de preparação da linha para mudar de um lote para outro varia de cinco a dez minutos. Quando é necessário fazer a limpeza, este tempo sobe para cerca de uma hora e qua- renta minutos, ou seja, o tempo de preparação é dependente da seqüência produtiva.

No dimensionamento de lotes, a capacidade produtiva é considerada em termos das horas disponíveis para produção no mês e de uma taxa média de produção por hora. Não é considerado o fato de que os tempos de preparação são dependentes da seqüência produtiva. Ou seja, diferentes programas resultam em diferentes seqüências, sendo que algumas podem demandar maior consumo de capacidade devido à necessidade de mais preparações, podendo inviabilizar alguns programas de produção. Portanto, a empresa freqüentemente tem dificuldades em coordenar, de forma eficaz, o dimensionamento de lotes com o seqüenciamento da produção, pois, uma vez definidos os tamanhos de lote, pode não ser possível encontrar uma seqüência de produção que seja viável do ponto de vista da capacidade disponível.

\section{Modelagem}

O modelo a seguir considera as decisões de dimensionamento e seqüenciamento de lotes de forma integrada, num ambiente monoestágio, uma máquina, com tempos de preparação dependentes da seqüência. A capacidade da linha de produção é limitada pela capacidade do equipamento gargalo (no caso, o misturador). Diversos produtos disputam recursos limitados sob condições de demanda dinâmica e horizonte de planejamento discreto e finito. Conforme o gerente da fábrica, o objetivo principal é satisfazer a demanda minimizando os custos de horas extras e os custos de manter estoques no período.

Os problemas de dimensionamento de lotes e seqüenciamento da produção, embora bastante relacionados, são freqüentemente tratados separadamente na literatura. Diversos modelos e métodos de solução para o problema de dimensionamento de lotes (lot sizing) e programação da produção (scheduling) podem ser encontrados em Johnson e Montgomery (1974), Hax e Candea (1984), Winston (1991), Askin e Standridge (1993), Williams (1993), Graves et al. (1993), Gershwin (1994), Nahmias (1995), Graham et al. (1979). Em Maes e Wassenhove (1988) e Trigeiro et al. (1989) são tratados apenas problemas de dimensionamento de lotes. Enquanto que em Lawler et al. (1993), Allahverdi et al. (1999) e Potts e Kovalyov (2000) são encontrados modelos de programação. No entanto, conforme Drexl e Kimms (1997) e Karimi et al. (2003), a tendência mais recente é combinar o problema de dimensionamento de lotes às decisões de programação da produção (lot-sizing and scheduling problems ou lot-scheduling). Diversos trabalhos são encontrados na literatura nesta linha, como Fleishmann (1994), Drexl e Haase (1995), Fleischmann e Meyr (1997), Salomon et al. (1997), Laguna (1999), Araújo e Arenales (2003), Meyr (2000), Clark e 
Clark (2000), Staggemeier e Clark (2001), Meyr (2002), Toledo et al. (2002), Araújo et al. (2004), Clark (2003), Haase (1996), Haase e Kimms (2000), Rangel e Ferreira (2003) e Luche e Morabito (2005).

Estes trabalhos apresentam diferentes modelagens para o problema de dimensionamento e seqüenciamento de lotes, bem como diferentes métodos de solução. Fleishmann (1994) apresenta uma reformulação do DLSP (Discrete Lot Sizing and Scheduling Problem) como um problema do caixeiro viajante com janelas de tempo e propõe uma heurística para resolvê-lo. Salomon et al. (1997) resolvem um problema semelhante por meio de um método ótimo baseado em programação dinâmica. Drexl e Haase (1995) apresentam o PLSP (Proportional Lot Sizing and Scheduling Problem), e um método de solução baseado em programação dinâmica. Haase (1996) apresenta uma variação do problema capacitado CLSP (Capacitated Lot Sizing and Scheduling Problem) e propõe um método de solução heurístico baseado em regras de prioridades. Fleischmann e Meyr (1997) formulam o chamado GLSP (General Lot Sizing Problem) e propõem três algoritmos de busca local para resolvê-lo. Em Meyr (2000) e Meyr (2002) são formuladas extensões do GLSP, que são resolvidas por meio de técnicas combinadas de reotimização dual e heurísticas de busca local.

Laguna (1999), Clark e Clark (2000) e Clark (2003) também apresentam formulações linear inteira mistas (MIP- Mixed Integer Programming) para o problema de dimensionamento e seqüenciamento de lotes enfatizando diferentes aspectos. Quanto aos métodos de solução, Laguna (1999) desenvolve um método de Busca Tabu com memória de curto prazo e os demais trabalham com procedimentos heurísticos baseados em MIP. Araujo e Arenales (2003), Araújo et al. (2004), Toledo et al. (2002), Rangel e Ferreira (2003) e Luche e Morabito (2005) apresentam formulações para problemas em fábricas brasileiras de fundição, de refrigerante e de grãos eletrofundidos. Estes problemas foram resolvidos por métodos heurísticos nos três primeiros trabalhos citados. Em Rangel e Ferreira (2003) é apresentado um método exato baseado nos métodos de planos de corte e branch and bound (branch and $c u t$ ). Luche e Morabito (2005) resolvem exemplos reais utilizando o software GAMS/CPLEX.

O modelo matemático que mais se aproxima de uma representação do presente problema é o GLSP-ST ( $G e$ neral Lot Sizing Problem - Setup Times) proposto por Meyr (2000), que considera a perda de capacidade resultante dos tempos de preparação dependentes da seqüência. Hax e Candea (1984) apresentam um modelo de dimensionamento de lotes capacitado que representa bem as considerações de utilização de horas extras para aumentar a capacidade produtiva, penalizando os custos de produção.

\subsection{Modelo matemático}

O modelo a seguir é resultado de uma combinação e adaptação dos modelos de Meyr (2000) e Hax e Candea (1984), sob as seguintes considerações:

- Como os lotes de produção têm tamanhos diferentes dependendo da densidade de cada produto e é inviável produzir menos que uma batelada, admite-se que a unidade de produção é uma batelada, independente do seu tamanho (em peso ou volume). As demandas por produto são agregadas e aproximadas pelos múltiplos dos tamanhos dos lotes. Isto de certa forma já é feito pelo departamento de vendas da empresa;

- A empresa produz cerca de 180 produtos. Para tornar o modelo mais tratável computacionalmente, os produtos são agregados em pouco mais de 20 famílias. Cada família só tem produtos pertencentes ao mesmo grupo de contaminação e com características comuns, como tempo de processamento e quantidade por batelada; e

- Quando não existe risco de contaminação residual, o tempo de preparação entre um lote e outro é pequeno (menos de 10 minutos), tanto entre produtos dentro da mesma família quanto entre famílias diferentes. Note que a desagregação dos produtos de uma família é um procedimento simples, uma vez que os tempos de preparação entre estes produtos são pequenos. Por simplicidade, tempos de preparação pequenos são desprezados.

Os índices do modelo são:

$i$ família, $i=1, \ldots, N$

$t$ período, $t=1, \ldots, T$

$s$ subperíodo, $s=1, \ldots, S$

em que, $N$ número de famílias,

$T$ número de períodos do horizonte de planejamento,

$S$ total de subperíodos (ao longo de todos os $T$ períodos).

No presente modelo o período $t$ corresponde a uma semana e é dividido em uma quantidade fixa $S_{t}$ de subperíodos, que também pode ser interpretada como a quantidade máxima permitida de preparações (por exemplo, se $S_{t}=N$, então todas as famílias podem ser produzidas em uma semana). Não existe sobreposição entre os subperíodos e o tamanho de cada subperíodo é uma variável de decisão, podendo inclusive ser nulo (sem nenhuma produção). Os subperíodos podem ser vistos como artifícios de modelagem para considerar as trocas de produtos num período. O tamanho do subperíodo $s$ depende do tempo de preparação e da quantidade produzida em $s$. Se um subperíodo tem comprimento zero, o estado de preparação da máquina é conservado. Isto é, se depois de um subperíodo sem produção, ocorrer a produção da mesma família, não é incorrido um novo tempo de preparação.

A sequiência de subperíodos consecutivos em que uma mesma família é produzida define um lote, e a quantida- 
de produzida durante estes subperíodos define o tamanho do lote. Observe que um lote pode continuar ao longo de diversos subperíodos e períodos, e é independente da estrutura de tempo discreto dos períodos. Os subperíodos fornecem o número, o tamanho e a seqüência dos lotes.

Os parâmetros do modelo são:

$C_{t}$ tempo disponível (capacidade) no período $t$.

$p_{i} \quad$ tempo necessário para produzir uma unidade da família $i$.

$l m_{i}$ lote mínimo da família $i$ (unidades).

$h_{i} \quad$ custo de manter uma unidade de estoque da família $i$ por um período $t$.

$c o_{t}$ custo unitário de hora extra no período $t$.

$s t_{j i}$ tempo de preparação para mudar da família $j$ para a família $i\left(\operatorname{com} s t_{i i}=0\right)$.

$d_{i t}$ demanda da família $i$ no período $t$ (unidades).

$I_{i 0}$ estoque inicial da família $i$ no começo do horizonte de planejamento (unidades).

$x_{i 0}$ indica se a linha está preparada para produzir a família $i$ no começo do horizonte de planejamento $\left(x_{i 0}=1\right)$ ou não $\left(x_{i 0}=0\right)$.

$u_{t}$ limite máximo de horas extras permitidas no período $t$.

As variáveis de decisão do modelo são:

$I_{i t}$ estoque da família $i$ no fim do período $t$ (unidades).

$q_{i s}$ tamanho do lote da família $i$ produzido no subperíodo $s$ (unidades). O tamanho do lote é múltiplo do número de bateladas, e, portanto, deve ser uma variável inteira.

$x_{i s}$ indica se a linha está preparada para produzir a família $i$ no subperíodo $s\left(x_{i s}=1\right)$ ou não $\left(x_{i s}=0\right)$.

$y_{j i s}$ indica se ocorre troca das famílias $j$ para $i$ no subperíodo $s\left(y_{j i s}=1\right)$ ou não $\left(y_{j i s}=0\right)$.

$O_{t}$ quantidade de horas extras utilizadas no período $t$.

O seguinte modelo é proposto para representar o presente problema:

Minimizar

$\sum_{i=1}^{N} \sum_{t=1}^{T} h_{i t} I_{i t}+\sum_{t=1}^{T} c o_{t} O_{t}$

$I_{i t}=I_{i, t-1}+\sum_{s \in S_{i}} q_{i s}-d_{i t} \quad \forall t, i$

$\sum_{i=1}^{N} \sum_{s \in S_{t}} p_{i} q_{i s}+\sum_{i=1}^{N} \sum_{j=1}^{N} \sum_{s \in S_{t}} s t_{j i} y_{j i s} \leq C_{t}+O_{t} \quad \forall t$

$p_{i} q_{i s} \leq\left(C_{t}+u_{t}\right) x_{i s} \quad \forall i, t, s \in S_{t}$

$\sum_{i=1}^{N} x_{i s}=1 \quad \forall s$

$$
\begin{aligned}
& y_{j i s} \geq x_{j, s-1}+x_{i s}-1 \quad \forall i, j, s \\
& q_{i s} \geq \operatorname{lm}_{i}\left(x_{i s}-\mathrm{x}_{i, s-1}\right) \quad \forall s, i \\
& x_{i s} \in\{0,1\} \quad \forall s, i \\
& I_{i t}, y_{j i s} \geq 0,0 \leq y_{j i s} \leq 1 \quad \forall i, j, s, t \text { para } i \neq j \\
& q_{i s} \geq 0, q_{i s} \text { inteiro, } \quad \forall i, s \\
& 0 \leq O_{t} \leq u_{t} \quad \forall t
\end{aligned}
$$

A função objetivo (1) expressa o critério de desempenho procurado pela empresa, que é minimizar os custos de estocagem $\sum_{i=1}^{N} \sum_{t=1}^{T} h_{i t} I_{i t}$ e horas extras $\sum_{t=1}^{T} \operatorname{co} O_{t}$. Note que esta função objetivo não considera os custos de preparação, diferente dos modelos de Hax e Candea (1984) e Meyr (2000). Conforme o gerente da fábrica, se existe capacidade disponível, é possível realizar preparações adicionais sem necessariamente incorrer em custos adicionais relevantes. Isto ocorre porque as preparações consomem basicamente apenas o recurso mão-de-obra, e o nível de força de trabalho é fixo de um período para outro. Portanto, basta considerar que os tempos de preparação consomem capacidade disponível.

As restrições (2) são de balanceamento de estoque: a quantidade de estoque em mãos $I_{i t}$ de uma família $i$ no fim da semana $t$ deve ser igual à quantidade de estoque em mãos $I_{i, t-1}$ no início da semana (ou seja, do fim da semana anterior), mais a somatória $\sum_{s \in S_{i}} q_{i s}$ das quantidades da família $i$ produzidas nos subperíodos $s$ da semana $t$, menos a quantidade demandada $d_{i t}$ da família $i$ na semana $t$.

As restrições (3) se referem à capacidade produtiva, considerada em termos de tempo e correspondendo aos turnos trabalhados dentro da semana, mais as possíveis horas extras necessárias para atender à demanda do período. Os tempos de preparação referentes às trocas de famílias acarretam perda da capacidade. Desta forma, a somatória $\sum_{i=1}^{N} \sum_{s \in S_{i}} p_{i} q_{i s}$, dos tempos necessários para a produção das famílias nos subperíodos, mais a somatória $\sum_{i=1}^{N} \sum_{j=1}^{N} \sum_{s \in S_{i}} s t_{j i} y_{j i s}$ dos tempos necessários para a preparação da linha toda vez que ocorrem trocas de famílias, não deve ser superior à quantidade disponível de tempo na semana (horas normais $C_{t}$ ), mais o número de horas extras necessárias $O_{t}$. Note que se a família $i$ for produzida no subperíodo $s$, então, o tamanho deste subperíodo é $p_{i} q_{i s}$, mais um eventual tempo de preparação $s t_{j i} y_{j i s}$ (Figura 2).

As restrições (4) garantem que a produção de uma família $i$ só pode ocorrer no subperíodo $s$ do período $t$ se 
$(t)$

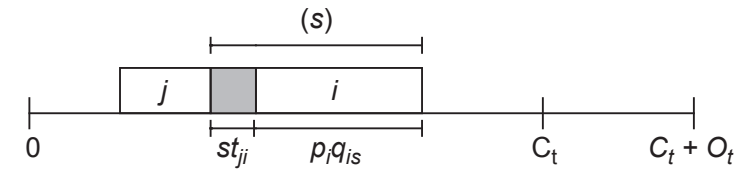

Figura 2. Esquema para ilustrar a capacidade produtiva (restrição 3).

a linha estiver preparada (limpa) para esta família neste subperíodo. As restrições (5) garantem que a linha só pode estar preparada para uma única família no subperíodo $s$. As restrições (6) relacionam os estados de preparação e os indicadores de mudança, ou seja, toda vez que há uma mudança na linha de produção de uma família $i$ para uma família $j$, deve haver uma mudança no estado de preparação da linha. Note que se $x_{i, s-1}=1$ e $x_{j s}=1$, então (6) garante que $y_{j i s} \geq 1$.

As restrições (7) impõem a produção de um lote mínimo $l m_{i}$ da família $i$ no subperíodo $s$ se a linha não estava preparada em $s-1\left(x_{i, s-1}=0\right)$ e estava preparada em $s\left(x_{i, s}=1\right)$. Estas restrições são necessárias uma vez que a matriz de tempos de preparação não satisfaz a desigualdade triangular, ou seja, $s t_{j k}+s t_{k i} \geq s t_{j i}, \forall i, j, k=1, \ldots, N$, nem sempre é válido. Para um melhor entendimento da importância destas restrições, considere as famílias $i, j$ e $k$, conforme Figura 3. Suponha que no subperíodo $s-1$ ocorra a produção da família $j$ (Figura 3a), a linha fica com resíduos de $j$ que são contaminantes para a família $i$, sendo necessário fazer uma limpeza na linha para viabilizar a produção da família $i$ no subperíodo seguinte $s$. Se ao invés disto produz-se no subperíodo $s$ uma família $k$, que não é contaminada pelos resíduos da família $j$ e não contamina a família $i$, esta família 'limpa' a linha e temse um tempo de preparação $s t_{j k}$ de $j$ para $k$ (Figura 3b). E para produzir no subperíodo $s+1$ a família $i$ depois da família $k$, há um tempo de preparação $s t_{k i}$ (Figura 3c). Existem exemplos na indústria de rações em que a soma dos tempos de preparação da sequiência $j-k$-i (i.e., $s t_{j k}+s t_{k i}$ ) é menor que o tempo de preparação da seqüência $j-i$ (i.e., $s t_{i j}$ ) (veja Tabela 2 na seção 4$)$.

Note que sem as restrições (7), o modelo poderia incorretamente produzir uma quantidade nula da família $k$ no subperíodo $s$ (i.e., $q_{k s}=0$ ), para, então, produzir a família $i$ no subperíodo seguinte $s+1$. As restrições (8), (9) e (10) são de não negatividade e integralidade das variáveis. Conforme mencionado, o estoque em mãos $I_{i t}$ da família $i$ no período $t$ deve ser não negativo, pois não são permitidos pedidos pendentes. A quantidade produzida $q_{i s}$ da família $i$ no subperíodo $s$, além de ser não negativa, deve ser uma variável inteira medida em número de bateladas.

Convém observar que, diferente do modelo de Meyr (2000), a variável $y_{j i s}$ não é penalizada na função objetivo

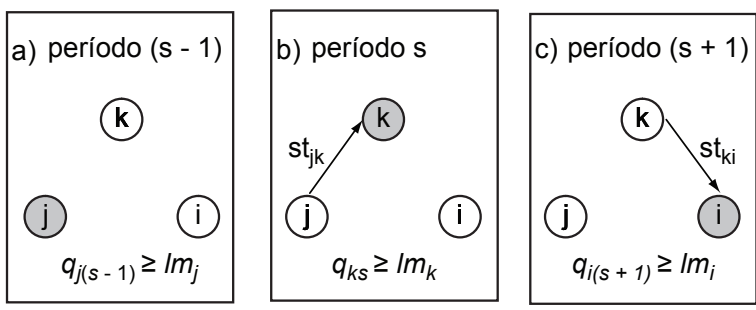

Figura 3. Exemplo ilustrativo que viola a desigualdade triangular.

(1) do modelo acima. Quando não há capacidade disponível em certo período $t$ (veja restrição (3)), é necessário utilizar horas extras neste período, que, então, são penalizadas na função objetivo. Neste caso, neste período $t$ (restrição (3)) os tempos de preparação são otimizados de forma a minimizar o impacto das horas extras deste período no custo total. O que faz com que as variáveis $y_{j i s}$ envolvidas neste período $t$ resultem binárias, sem necessidade de impor esta condição nas restrições (9). Isto também pode ser explicado pelo seguinte argumento: dada uma solução ótima com valores $y_{j i s}$ fracionais, sempre é possível encontrar uma solução ótima alternativa, ou seja, com o mesmo valor da função objetivo, simplesmente fixando as variáveis $y_{j i s}$ em 0 , quando $0<y_{j i s}<1$, e em 1, quando $y_{j i s}>1$.

Finalmente, as restrições (11) referem-se aos limites de horas extras. Estas horas são regulamentadas pelas leis trabalhistas e podem ser negociadas pelos sindicatos de cada indústria. No presente estudo de caso, além deste limite, existem outros relacionados às metas de planejamento estratégico da empresa. Admite-se o limite $u_{t}$ como o máximo de horas extras permitidas por lei, uma vez que elas são minimizadas na função objetivo (1).

Este modelo foi definido considerando a produção de $N$ produtos (famílias), em $T$ períodos e em um total de $S$ subperíodos, envolvendo $[N(N S+2 S+T)+T+1]$ variáveis, das quais $(N S)$ são binárias e $(N S)$ são inteiras. Se a variável $y_{j i s}$ for modelada como binária tem-se $[N S(N+1)]$ variáveis binárias.

\section{Resultados}

Nesta seção, são apresentados os resultados obtidos com o modelo (1)-(11). Para resolvê-lo, foi utilizada a linguagem de modelagem algébrica GAMS (Brooke et al., 1992) com o solver CPLEX (versão 7). Para realização dos experimentos computacionais, foi utilizado um microcomputador com processador AMD Atlhon 133 Mhz com 512 Mb de memória RAM e sistema operacional Windows XP.

Inicialmente, para verificar a consistência do modelo foram realizados diversos testes com exemplos simpli- 
ficados e ilustrativos. O número de períodos, subperíodos e famílias foram reduzidos e os parâmetros foram estimados de forma que os resultados se comportassem de acordo com os valores esperados. Os detalhes destes experimentos estão descritos em Toso (2003). Notou-se que o modelo é consistente, mas bastante sensível aos dados de entrada.

A seguir são apresentados os resultados da aplicação do modelo com dados reais da empresa, referentes a um mês de produção. $\mathrm{O}$ mês escolhido corresponde a um mês do período de chuvas, em que se tem uma maior variedade de famílias, porém demandadas em menores quantidades. A formulação (1)-(11) resulta em 40661 variáveis (das quais 1764 são inteiras e 1764 são binárias) e 40749 restrições (não considerando as variáveis $y_{i i s}$ como binárias). Nos diversos testes computacionais realizados, observou-se que, após certo tempo de processamento, as soluções encontradas não apresentam melhoria significativa. Por isso um limite para o tempo de processamento do modelo foi arbitrariamente fixado em 3 horas.

\subsection{Parâmetros do modelo}

Os parâmetros do modelo: custo de manter uma unidade em estoque por família $\left(h_{i}\right)$, custo unitário de hora extra $\left(c o_{t}\right)$, limite de horas normais $\left(C_{t}\right)$, limite de horas extras $\left(u_{t}\right)$, tempo necessário para produção de uma batelada de cada família $\left(p_{i}\right)$, matriz de tempos de preparação dependentes da sequiência $\left(s t_{j i}\right)$ e demandas por família $\left(d_{i t}\right)$, foram fornecidos pela empresa. A capacidade disponível (em horas) $C_{t}$, o limite de horas extras $u_{t}$ e o custo unitário de hora extra $c o_{t}$ são constantes e iguais a 64, 16 e 859,2, respectivamente. Os demais dados encontram-se nas Tabelas 1, 2 e 3. Cabe ressaltar que, para proteger as informações fornecidas pela empresa, estes dados foram distorcidos, mantendo-se apenas sua proporcionalidade.

Observe que a capacidade necessária para produzir a quantidade demandada nos períodos $t 1, t 2$ e $t 3$ são menores que a capacidade produtiva, ou seja, existe capacidade ociosa nestes períodos (Tabela 3). Entretanto, no período $t 4$ ocorre um pico de demanda que supera a capacidade disponível no período normal, ou seja, sem a utilização de horas extras. Para programar a produção, a empresa opta por duas alternativas: carregar estoques ou utilizar horas extras. Cabe ressaltar que as demandas foram estimadas pelos departamentos de vendas e PCP da empresa, ou seja, estes dados já sofreram alguma manipulação de forma a adequar a demanda semanal à capacidade disponível em cada período. Desta forma, estes dados já embutem algumas decisões de estocagem por parte da empresa.

\subsection{Resultados obtidos}

Implementando o modelo (1)-(11) no software GAMS/ CPLEX com os parâmetros da empresa, sem tolerância no gap de otimalidade, obteve-se um programa de produ- ção com custo de 5535 unidades monetárias após 3 horas de processamento. Comparada ao limitante inferior calculado pelo GAMS/CPLEX, esta solução encontra-se a, no máximo, $43,41 \%$ do valor ótimo, isto é, o gap em relação ao limitante inferior é grande.

Nesta solução inicial (sem garantia de otimalidade), observou-se que algumas variáveis $y_{j i s}$ assumem valores positivos, mesmo quando não há quantidades produzidas. Conforme discussão anterior, as restrições (7) impedem que, estando a linha preparada para um produto $j$ no subperíodo $s-1\left(x_{j, s-1}=1\right)$, ela seja preparada para um produto $i$ no subperíodo $s\left(x_{i s}=1\right)$ sem que ocorra produção de um lote mínimo $\left(q_{i s} \geq \operatorname{lm} m_{i}\right)$. Entretanto, pode ocorrer que a máquina não esteja preparada em $(s-1)$ para $j\left(x_{j, s-1}=0\right)$ ou para $i\left(x_{i, s-1}=0\right)$, e não esteja preparada em $s$ para $i\left(x_{i s}=0\right)$ ou para $j\left(x_{j s}=0\right)$. Neste caso, pela restrição (7) tem-se que $q_{i s} \geq 0$, e pela restrição (6), $y_{j i s} \geq-1$. Considerando que $0 \leq y_{j i s} \leq 1$ conforme (9), a solução do modelo pode atribuir valores positivos a algumas variáveis $y_{j i s}$ o que é inconsistente do ponto de vista lógico, apesar de não interferir na sequiência produtiva da solução gerada. Além disso, note que na matriz da Tabela 3 que, por conveniência, os tempos de preparação pequenos foram desprezados, resultando em muitos valores nulos na matriz. Com isso, as variáveis $y_{j i s}$ correspondentes ficam livres para assumir valores positivos, mesmo quando não

Tabela 1. Consumo de capacidade por produto $i\left(p_{i}\right)$, custos* de manter uma unidade em estoque $\left(h_{i}\right)$.

\begin{tabular}{ccc}
\hline $\boldsymbol{i}$ & $\boldsymbol{p}_{\boldsymbol{i}}$ & $\boldsymbol{h}_{i}$ \\
\hline fam 1 & 0,4 & 660,0 \\
fam 2 & 0,4 & 170,0 \\
fam 3 & 0,4 & 851,0 \\
fam 4 & 0,4 & 151,2 \\
fam5 & 0,2 & 103,4 \\
fam6 & 0,4 & 110,0 \\
fam 7 & 0,2 & 421,0 \\
fam 8 & 0,2 & 443,0 \\
fam 9 & 0,2 & 392,0 \\
fam 10 & 0,2 & 488,0 \\
fam 11 & 775,0 \\
fam 12 & 0,2 & 591,0 \\
fam 13 & 0,2 & 849,0 \\
fam 14 & 0,3 & 922,0 \\
fam 15 & 0,3 & 312,0 \\
fam 16 & 0,2 & 432,0 \\
fam 17 & 0,2 & 621,0 \\
fam 18 & 0,2 & 592,0 \\
fam 19 & 0,4 & 137,1 \\
fam 20 & 0,6 & 102,6 \\
fam 21 & 0,6 & 446,0 \\
\hline & 0,3 &
\end{tabular}

*em unidades monetárias (u.m.). 
Tabela 2. Matriz dos tempos de preparação $\left(s t_{i j}\right)$.

\begin{tabular}{|c|c|c|c|c|c|c|c|c|c|c|c|c|c|c|c|c|c|c|c|c|c|}
\hline \multirow[t]{2}{*}{$\mathbf{i}$} & \multicolumn{21}{|c|}{ fam } \\
\hline & 1 & 2 & 3 & 4 & 5 & 6 & 7 & 8 & 9 & 10 & 11 & 12 & 13 & 14 & 15 & 16 & 17 & 18 & 19 & 20 & 21 \\
\hline 1 & 0 & 0 & 1,67 & 1,67 & 1,67 & 0 & 1,67 & 1,67 & 1,67 & 1,67 & 0 & 1,67 & 0 & 0 & 0 & 0 & 0 & 0 & 0 & 0 & 0 \\
\hline 2 & 1,67 & 0 & 1,67 & 1,67 & 1,67 & 0 & 1,67 & 1,67 & 1,67 & 1,67 & 1,67 & 1,67 & 1,67 & 0 & 1,67 & 0 & 0 & 0 & 0 & 0 & 0 \\
\hline 3 & 0 & 0 & 0 & 0 & 0 & 0 & 1,67 & 1,67 & 1,67 & 1,67 & 0 & 1,67 & 0 & 0 & 0 & 0 & 0 & 0 & 0 & 0 & 0 \\
\hline 4 & 0 & 0 & 0 & 0 & 0 & 0 & 1,67 & 1,67 & 1,67 & 1,67 & 0 & 1,67 & 0 & 0 & 0 & 0 & 0 & 0 & 0 & 0 & 0 \\
\hline 5 & 0 & 0 & 0 & 0 & 0 & 0 & 1,67 & 1,67 & 1,67 & 1,67 & 0 & 1,67 & 0 & 0 & 0 & 0 & 0 & 0 & 0 & 0 & 0 \\
\hline 6 & 1,67 & 0 & 0 & 1,67 & 1,67 & 0 & 1,67 & 1,67 & 1,67 & 1,67 & 1,67 & 1,67 & 1,67 & 0 & 1,67 & 0 & 0 & 0 & 0 & 0 & 0 \\
\hline 7 & 0 & 0 & 0 & 0 & 0 & 0 & 0 & 0 & 0 & 0 & 0 & 0 & 0 & 0 & 0 & 0 & 0 & 0 & 0 & 0 & 0 \\
\hline 8 & 0 & 0 & 0 & 0 & 0 & 0 & 0 & 0 & 0 & 0 & 0 & 0 & 0 & 0 & 0 & 0 & 0 & 0 & 0 & 0 & 0 \\
\hline 9 & 0 & 0 & 0 & 0 & 0 & 0 & 0 & 0 & 0 & 0 & 0 & 0 & 0 & 0 & 0 & 0 & 0 & 0 & 0 & 0 & 0 \\
\hline 10 & 0 & 0 & 0 & 0 & 0 & 0 & 0 & 0 & 0 & 0 & 0 & 0 & 0 & 0 & 0 & 0 & 0 & 0 & 0 & 0 & 0 \\
\hline$\Xi 11$ & 1,67 & 0 & 0 & 1,67 & 1,67 & 0 & 0 & 0 & 0 & 0 & 0 & 1,67 & 1,67 & 0 & 1,67 & 0 & 0 & 0 & 0 & 0 & 0 \\
\hline 12 & 0 & 0 & 0 & 0 & 0 & 0 & 0 & 0 & 0 & 0 & 0 & 0 & 0 & 0 & 0 & 0 & 0 & 0 & 0 & 0 & 0 \\
\hline 13 & 0 & 0 & 0 & 0 & 0 & 0 & 0 & 0 & 0 & 0 & 0 & 0 & 0 & 0 & 0 & 0 & 0 & 0 & 0 & 0 & 0 \\
\hline 14 & 0 & 0 & 0 & 0 & 0 & 1,67 & 1,67 & 1,67 & 1,67 & 0 & 0 & 1,67 & 0 & 0 & 1,67 & 1,67 & 0 & 0 & 0 & 0 & 1,67 \\
\hline 15 & 0 & 0 & 0 & 0 & 0 & 0 & 0 & 0 & 0 & 0 & 0 & 0 & 0 & 0 & 0 & 0 & 0 & 0 & 0 & 0 & 0 \\
\hline 16 & 0 & 0 & 0 & 0 & 0 & 0 & 0 & 0 & 0 & 0 & 0 & 0 & 0 & 0 & 1,67 & 0 & 0 & 0 & 0 & 0 & 0 \\
\hline 17 & 0 & 0 & 0 & 0 & 0 & 0 & 0 & 0 & 0 & 0 & 0 & 0 & 0 & 0 & 1,67 & 0 & 0 & 0 & 0 & 0 & 0 \\
\hline 18 & 1,67 & 1,67 & 1,67 & 1,67 & 1,67 & 1,67 & 1,67 & 1,67 & 1,67 & 1,67 & 1,67 & 1,67 & 1,67 & 1,67 & 1,67 & 1,67 & 0 & 0 & 1,67 & 1,67 & 1,67 \\
\hline 19 & 1,67 & 1,67 & 1,67 & 1,67 & 1,67 & 1,67 & 1,67 & 1,67 & 1,67 & 1,67 & 1,67 & 1,67 & 1,67 & 1,67 & 1,67 & 1,67 & 1,67 & 1,67 & 0 & 1,67 & 1,67 \\
\hline 20 & 1,67 & 1,67 & 1,67 & 1,67 & 1,67 & 1,67 & 1,67 & 1,67 & 1,67 & 1,67 & 1,67 & 1,67 & 1,67 & 1,67 & 1,67 & 1,67 & 1,67 & 1,67 & 1,67 & 0 & 1,67 \\
\hline 21 & 1,67 & 0 & 0 & 1,67 & 0 & 0 & 0 & 0 & 0 & 0 & 0 & 1,67 & 1,67 & 0 & 1,67 & 0 & 0 & 0 & 0 & 0 & 0 \\
\hline
\end{tabular}

Tabela 3. Demanda mensal (bateladas) por período $\left(d_{i}\right)$.

\begin{tabular}{lrrrrr}
\hline \multicolumn{1}{c}{ família } & $\boldsymbol{t} \mathbf{1}$ & $\boldsymbol{t} \mathbf{2}$ & $\boldsymbol{t 3}$ & $\boldsymbol{t 4}$ & total \\
\hline fam 1 & 0 & 0 & 0 & 0 & 0 \\
fam 2 & 2 & 3 & 9 & 1 & 15 \\
fam 3 & 9 & 16 & 9 & 25 & 59 \\
fam 4 & 0 & 0 & 1 & 0 & 1 \\
fam 5 & 25 & 15 & 2 & 5 & 47 \\
fam 6 & 0 & 0 & 0 & 0 & 0 \\
fam 7 & 15 & 16 & 12 & 11 & 54 \\
fam 8 & 29 & 29 & 32 & 52 & 142 \\
fam 9 & 40 & 32 & 32 & 52 & 156 \\
fam 10 & 58 & 57 & 65 & 79 & 259 \\
fam11 & 2 & 6 & 6 & 5 & 19 \\
fam 12 & 2 & 1 & 1 & 0 & 4 \\
fam 13 & 0 & 1 & 1 & 1 & 3 \\
fam 14 & 12 & 15 & 20 & 19 & 66 \\
fam 15 & 1 & 1 & 0 & 0 & 2 \\
fam 16 & 1 & 0 & 0 & 0 & 1 \\
fam17 & 10 & 3 & 3 & 3 & 19 \\
fam 18 & 0 & 0 & 0 & 0 & 0 \\
fam 19 & 0 & 1 & 1 & 4 & 6 \\
fam 20 & 4 & 0 & 4 & 1 & 9 \\
fam 21 & 35 & 38 & 46 & 47 & 166 \\
\hline total & 245 & 234 & 244 & 305 & \\
\hline cap. necessária & 57,5 & 56,4 & 61,3 & 74,9 & \\
\hline & & & & &
\end{tabular}

ocorre efetivamente uma preparação (veja restrição (3)). Nos experimentos observou-se que, nestes casos, a variável $y_{j i s}$, freqüentemente, assume valores positivos.

$\mathrm{Na}$ tentativa de contornar parcialmente este problema, também foram realizados testes declarando a variável $y_{\text {iis }}$ como binária. Ao executar o modelo no GAMS/CPLEX durante 3 horas, obteve-se a mesma solução (sem garantia de otimalidade). Nestes experimentos observou-se que a variável $y_{j i s}$ ainda pode assumir valores 1, mesmo quando não ocorre preparação. Outros experimentos foram realizados penalizando as variáveis $y_{j i s}$ na função objetivo, na tentativa de acelerar a convergência para a solução ótima. No entanto, os resultados não melhoraram, mesmo impondo limite de bem mais de 3 horas de processamento para estes experimentos. Na tentativa de encontrar resultados melhores, foram realizados os seguintes testes adicionais:

Estratégia A. Foram realizados alguns experimentos incorporando-se desigualdades válidas ao modelo. Primeiramente foram incluídos dois grupos de restrições que, de acordo com Fleischmann e Meyr (1997), reduzem o espaço de soluções (sem perda de otimalidade) e contribuem para evitar algumas redundâncias do modelo:

$$
\sum_{j, i, j \neq i} y_{j, i, s-1} \geq \sum_{j, i, j \neq i} y_{j, i, s} \quad \forall t, s=(f+2), \ldots, l_{t}
$$




$$
q_{i, s} \leq\left(C_{t}+u_{t}\right) / p_{i}^{*}\left(2-\sum_{j} y_{j, i, s-1}-y_{i i s}\right)
$$

em que, $f_{t}$ é o primeiro subperíodo do período $t$.

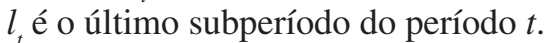

As restrições (12) ordenam a seqüência de preparações ao longo dos subperíodos (de cada período $t$ ), começando pelos subperíodos que envolvem troca de famílias $\left(\sum_{j, i, j \neq i} y_{j i s}=1\right)$, e deixando para o final os subperíodos sem troca de famílias $\left(\sum_{j, i, j \neq i} y_{j i s}=0\right.$, ou seja, com $\left.y_{i i s}=1\right)$, eventualmente sem produção. As restrições (13) evitam a produção de uma família em dois subperíodos consecutivos (de cada período $t$ ). Note que isto é equivalente a produção desta família num único subperíodo de duração maior. Por exemplo, a produção da família $j$ no subperíodo $s$ - 2, seguida da produção da família $i$ nos subperíodos $s$ - 1 e $s$, implica em: $y_{i i, s-1}=1$ e $y_{i i s}=1$; logo, a restrição (13) resulta em: $q_{i s} \leq 0$. Ou seja, esta restrição impede que ocorra a produção da mesma família $i$ nos dois subperíodos consecutivos $s-1$ e $s$.

Para avaliar se as restrições (12) e (13) melhoram a qualidade das soluções obtidas, estas foram incluídas no modelo (1)-(11). Nestes experimentos os resultados obtidos depois de 3 horas de processamento não melhoraram a solução já encontrada pelo modelo. Além disso, estas restrições não evitam que algumas variáveis $y_{j i s}$ assumam valor 1, mesmo quando não ocorre efetivamente uma preparação (conforme discutido anteriormente). Para evitar que variáveis $y_{j i s}$ possam assumir valores positivos sem necessidade, foram propostos os grupos de restrições:

$$
\sum_{j=1}^{N} y_{j i s} \leq x_{i s} \quad \forall i, s
$$

$$
y_{i i s}=0 \quad \forall i, s
$$

De acordo com as inequações (14), se a linha não está preparada para o produto $i$ no subperíodo $s\left(x_{i s}=0\right)$, então não pode ocorrer troca de produtos $j$ para $i$ no subperíodo $s$ (ou seja, $\sum_{j=1}^{N} y_{j i s} \leq 0$ ). Já as restrições (15) impõem

valores nulos para as variáveis $y_{i i s}$, uma vez que se sabe não existir tempos de preparação entre lotes do mesmo produto. Foram realizados experimentos com o modelo (1)-(11) junto com (12)-(13), junto com (14)-(15) e junto com (12)-(15). Nestes experimentos as restrições (14) e (15) melhoraram sensivelmente a solução do modelo (1)(11), conforme mostrado na Tabela 4. Este resultado sugere que o pré-processamento e os cortes introduzidos pelo solver CPLEX foram efetivos em eliminar soluções não relevantes do problema, tornando mais eficiente sua resolução.

Estratégia B. Na tentativa de melhorar a solução dos modelos (1)-(11) e (1)-(15) (Estratégia A), também foram realizados testes relaxando a condição de integralidade da quantidade produzida $q_{i s}$. A solução gerada foi manualmente arredondada para possíveis soluções inteiras, ou seja, os valores fracionários das variáveis $q_{i s}$ foram aproximados (para cima ou para baixo) para valores inteiros, avaliando a viabilidade de cada solução arredondada e o impacto nos custos. A aplicação desta estratégia no exemplo da empresa gerou apenas 3 valores de $q_{i s}$ fracionários que, depois de algumas tentativas de arredondamento, resultaram na solução inteira viável apresentada na Tabela 4. Observou-se, nestes experimentos, que as variáveis $y_{j i s}$ relacionadas a valores nulos da

\begin{tabular}{|c|c|c|c|c|c|c|c|c|}
\hline \multirow[t]{2}{*}{ Exp. } & \multirow[t]{2}{*}{$\mathbf{y}_{\mathrm{jis}}$} & \multirow{2}{*}{$\begin{array}{c}\text { Original } \\
(1)-(11)\end{array}$} & \multicolumn{2}{|c|}{ Estr. A } & \multirow{2}{*}{$\begin{array}{l}\text { Estr. B } \\
\text { relax } \mathbf{q}_{\text {is }}\end{array}$} & \multirow{2}{*}{$\begin{array}{l}\text { Estr. } \mathbf{C} \\
\text { seq. }{ }_{1}\end{array}$} & \multirow[t]{2}{*}{ f.o. } & \multirow[t]{2}{*}{ tempo } \\
\hline & & & (12)-(13) & (14)-(15) & & & & \\
\hline A1 & canalizada & $\mathrm{x}$ & & & & & 5535 & 18,3 \\
\hline A2 & canalizada & & $\mathrm{x}$ & & & & 7415 & 18,7 \\
\hline A3 & canalizada & & & $\mathrm{x}$ & & & 10455 & 66,7 \\
\hline A4 & canalizada & & $\mathrm{x}$ & $\mathrm{x}$ & & & 7713 & 54,0 \\
\hline A5 & canalizada & & & & $\mathrm{x}$ & & 3476 & 70,0 \\
\hline A6 & canalizada & & $\mathrm{x}$ & $\mathrm{x}$ & $\mathrm{x}$ & & 3511 & 58,3 \\
\hline A7 & canalizada & & & & & $\mathrm{x}$ & 4450 & 40,0 \\
\hline Ab1 & binária & $\mathrm{x}$ & & & & & 5535 & 15,0 \\
\hline $\mathrm{Ab} 2$ & binária & & $\mathrm{x}$ & & & & 10058 & 78,3 \\
\hline$A b 3$ & binária & & & $\mathrm{x}$ & & & 3458 & 110,0 \\
\hline $\mathrm{Ab} 4$ & binária & & $\mathrm{x}$ & $\mathrm{x}$ & & & 4085 & 133,3 \\
\hline Ab5 & binária & & & & $\mathrm{x}$ & & 3481 & 180,0 \\
\hline Ab6 & binária & & $\mathrm{x}$ & $\mathrm{x}$ & $\mathrm{x}$ & & 3863 & 138,3 \\
\hline $\mathrm{Ab} 7$ & binária & & & & & $\mathrm{x}$ & 4457 & 0,7 \\
\hline
\end{tabular}
matriz de tempos de preparação também assumem valo-

Tabela 4. Resumo dos resultados dos experimentos computacionais. 
res positivos, mesmo quando não há alteração no estado de preparação.

Estratégia C. Outros testes foram realizados com o modelo (1)-(11) seqüenciando apenas o primeiro período $t 1$, relaxando a preparação dependente nos demais períodos $t 2$, $t 3$ e $t 4$ e diminuindo suas capacidades. Para isto, foram alteradas no modelo as restrições correspondentes às restrições (4), (5), (6) e (7), de maneira que elas se tornassem válidas apenas para o primeiro período $t 1$ e aos seus respectivos subperíodos. Com esta alteração no modelo, nos períodos $t 2, t 3$ e $t 4$, foi feito apenas o dimensionamento dos lotes, sem seqüenciar a produção. Para considerar o tempo gasto nas preparações, foram realizados experimentos reduzindo a capacidade em uma preparação de 1,67 horas por período, ou seja, C'2 = C'3 $=\mathrm{C}^{\prime} 4=(64-1,67)=62,33 \mathrm{~h}$, cujos resultados aparecem na Tabela 4. Outros experimentos foram feitos prevendo uma preparação no período $t 2$ e duas preparações no período $t 3$ (com base em alguns resultados gerados pelo GAMS/CPLEX). Assim, a capacidade foi reduzida da seguinte forma: $\mathrm{C}^{\prime} 2=62,33 \mathrm{~h}, \mathrm{C}^{\prime} 3=64 \mathrm{~h}$ e C' $4=60,66 \mathrm{~h}$. Observou-se, nestes testes, que as soluções encontradas são bastante sensíveis às penalizações feitas na capacidade, como era esperado.

A Tabela 4 compara os resultados obtidos com o modelo original (1)-(11) e as estratégias A, B e C. Estas estratégias foram aplicadas tanto com $y_{j i s}$ canalizada $\left(0 \leq y_{j i s} \leq 1\right)$ conforme restrição (9) (veja experimentos A1-A7 da tabela), quanto com $y_{j i s}$ declarada como binária $\left(y_{j i s} \in\{0,1\}\right)$ (veja experimentos Ab1-Ab7 da tabela). A coluna "tempo" da tabela indica o tempo de processamento (em minutos) até obter a solução de cada experimento (note que os tempos são menores ou iguais ao limite de 3 horas). O experimento Ab3 (Estratégia A) gerou a melhor solução para este exemplo, com um custo de 3458 unidades monetárias, seguido dos experimentos A5 e Ab5 (Estratégia B).

Em relação aos tempos computacionais demandados pela solução do experimento Ab3, uma solução inicial com gap (relativo ao limitante inferior) de $56,23 \%$ é encontrada rapidamente pelo modelo (em cerca de 20 segundos). Depois de quase 2 horas de processamento, o modelo encontra a solução de custo 3458 unidades monetárias com gap de $15 \%$, que não melhora até mesmo quando o tempo de processamento é estendido para bem mais de 3 horas. Portanto, não se sabe se esta solução é ótima, e se não for, seu custo é no máximo $15 \%$ maior que o custo ótimo. Esta solução é apresentada em detalhes nas Tabelas 5 (dimensionamento de lotes) e 6 (seqüenciamento da produção).

Conforme se pode observar nas Tabelas 3 e 5, no primeiro período $(t 1)$, a demanda é completamente atendida, e ainda são produzidas para estoque 2 bateladas da família 19 e 4 da família 21. Pela Tabela 6 , sabe-se que para produzir a seqüência gerada pelo modelo é necessário fazer duas preparações neste período ( $s 10$ e $s 19)$. Portanto, a capacidade de tempo total prevista para este período é de 63,24 horas (59,9 horas para produção mais 3,34 horas para a preparação).

No segundo período ( $t 2)$ a demanda é atendida totalmente pelas quantidades produzidas, exceto pela família 19 que é atendida pelo estoque do período $t 1$. Neste período ainda é prevista a produção para estoque de 2 bateladas da família 9,5 bateladas da família 20 e 10 da família 21. Na Tabela 6, vê-se que a sequiência deste período necessita de apenas uma preparação, portanto o tempo total previsto é de 63,87 horas.

No terceiro período ( $t 3$ ) o programa de produção gerado atende completamente à demanda do período, exceto pela família 19 que utiliza 1 batelada do estoque, e pela família 20 que utiliza 4 bateladas produzidas anteriormente. Ainda é programada a produção de 19 bateladas de estoque para a família 21. Para produzir a seqüência prevista para este período, não é preciso realizar nenhuma preparação (Tabela 6), portanto a capacidade de tempo necessária é de 64 horas, que corresponde exatamente ao tempo para produção.

Finalmente, no quarto período, no qual a demanda prevista é superior à capacidade produtiva do período, a

Tabela 5. Dimensionamento de lotes do exp. Ab3.

\begin{tabular}{|c|c|c|c|c|c|}
\hline & $t 1$ & $t 2$ & t3 & $t 4$ & total \\
\hline fam 1 & 0 & 0 & 0 & 0 & 0 \\
\hline fam 2 & 2 & 3 & 9 & 1 & 15 \\
\hline fam3 & 9 & 16 & 9 & 25 & 59 \\
\hline fam 4 & 0 & 0 & 1 & 0 & 1 \\
\hline fam 5 & 25 & 15 & 2 & 5 & 47 \\
\hline fam 6 & 0 & 0 & 0 & 0 & 0 \\
\hline fam7 & 15 & 16 & 12 & 11 & 54 \\
\hline fam8 & 29 & 29 & 32 & 52 & 142 \\
\hline fam 9 & 40 & 34 & 32 & 50 & 156 \\
\hline $\operatorname{fam} 10$ & 58 & 57 & 65 & 79 & 259 \\
\hline fam 11 & 2 & 6 & 6 & 5 & 19 \\
\hline fam 12 & 2 & 1 & 1 & 0 & 4 \\
\hline fam 13 & 0 & 1 & 1 & 1 & 3 \\
\hline fam 14 & 12 & 15 & 20 & 19 & 66 \\
\hline fam 15 & 1 & 1 & 0 & 0 & 2 \\
\hline fam 16 & 1 & 0 & 0 & 0 & 1 \\
\hline fam 17 & 10 & 3 & 3 & 3 & 19 \\
\hline fam 18 & 0 & 0 & 0 & 0 & 0 \\
\hline fam 19 & 2 & 0 & 0 & 4 & 6 \\
\hline fam 20 & 4 & 5 & 0 & 0 & 9 \\
\hline $\operatorname{fam} 21$ & 39 & 48 & 65 & 14 & 166 \\
\hline capacidade & 59,9 & 62,2 & 64 & 64 & \\
\hline setup (hs) & 3,34 & 1,67 & 0 & 0 & \\
\hline tempo total & 63,24 & 63,87 & 64 & 64 & \\
\hline
\end{tabular}


demanda é atendida pelas quantidades produzidas mais 1 batelada estocada da família 20, 2 bateladas da família 9 e 33 bateladas em estoque da família 21. Da mesma maneira que no período anterior, a produção é seqüenciada de forma que não seja necessário realizar nenhuma preparação. O tempo total para produção também é de 64 horas.

Observe que, como a capacidade de cada período é de 64 horas de produção, não são utilizadas horas extras em nenhum período. Isto implica que o custo resultante deste programa de produção (3458 u.m.) corresponde apenas aos custos de manter estoques. Note na Tabela 6 que, na seqüência de produção resultante do modelo, algumas famílias exercem a função de 'limpante' como, por exemplo, a família 21 , que tem sua produção alocada para o subperíodo $s 24$. Isto ocorre porque a desigualdade triangular não é válida para o problema em questão. Neste caso, para produzir a família 9 depois da família 2 é necessário fazer uma limpeza (Tabela 2). Produzindo um lote da família 21 entre eles, a limpeza na linha se torna desnecessária.

\subsection{Comparação com solução praticada pela empresa}

O programa de produção da empresa consiste em produzir a cada semana, apenas a demanda prevista para a semana (chase strategy; Nahmias, 1995), procurando não carregar estoques de períodos anteriores, mas incorrendo quando necessário na utilização de horas extras. A empresa aposta nesta estratégia, pois considera que as incertezas em relação à demanda são bastante grandes. Desta forma, o programa de produção inicial da empresa coincide com a tabela de previsão de demanda (Tabela 3).

Quanto ao seqüenciamento, conforme descrito na seção 2, ele não é planejado no programa inicial, ficando a cargo do chão-de-fábrica. Por meio das ordens de fabricação reportadas da empresa, sabe-se que a produção deste mês foi seqüenciada de maneira que foram necessárias quatro preparações no período $t 1$, três no período $t 2$, quatro no período $t 3$ e duas no período $t 4$. Considerando o tempo necessário para produzir a demanda em cada semana (Tabela 3), mais o tempo gasto nas preparações, conclui-se que o tempo total (em horas) necessário por semana é de: 64,18 horas no período $t 1,61,41$ horas no período $t 2,67,98$ horas no período $t 3$ e 78,24 horas no período $t 4$ (compare com os tempos totais da Tabela 5).

Considerando os custos de horas extras, o programa da empresa resulta num custo total de 15809 unidades monetárias. Para mais detalhes desta análise, o leitor pode consultar Toso (2003). Comparando os programas de produção da empresa com o gerado pelo modelo, observa-se que este último consegue uma redução substancial no custo total (custo de horas extras e custo de estocagem) de 77,5\% (Tabela 7). 
Tabela 7. Comparação da solução da empresa e do modelo.

\begin{tabular}{lrl}
\hline solução da empresa & 15809 u.m. & \\
solução do modelo & 3481 u.m. & \\
diferença & 12268 u.m. & $(77,5 \%)$ \\
\hline
\end{tabular}

Este custo total é significativamente menor porque, além de antecipar a produção nos períodos em que existe capacidade ociosa, o modelo encontra seqüências de produção melhores, ou seja, com menos preparações. Cabe salientar que o programa de produção da empresa é cauteloso em relação ao pico de demanda previsto para o final do mês, ou seja, a programação da empresa aposta que ele não vai ocorrer. Se isto acontecer de fato, a estratégia de produção da empresa pode ser melhor. Entretanto, esta cautela da empresa em relação às incertezas da demanda pode ser contemplada no modelo por meio de análise de sensibilidade, alterando-se os parâmetros de demanda por valores menos otimistas e executando-se o programa para diversos cenários.

Outra aplicação do modelo pode ser feita utilizando-se o conceito de horizonte rolante. Inicialmente, antes do início da primeira semana, pode-se resolver o modelo para as quatro primeiras semanas (semanas $t 1-t 4$ ) e implementar apenas os resultados obtidos para a primeira semana (semana $t 1$ ). Em seguida, ao final da primeira semana e antes do início da segunda, pode-se acrescentar mais uma semana ao modelo (semana $t 5$ ), resolvê-lo para as quatro próximas semanas (semanas $t 2-t 5$ ) e implementar apenas os resultados obtidos para a "primeira" (semana $t 2$ ), e assim por diante.

Os resultados acima analisados referem-se a um mês de produção da empresa do período de 'águas', cuja característica particular é grande variedade de produtos demandados em pequenas quantidades. Em Toso (2003) são apresentados também os resultados de experimentos realizados com outro mês de produção da empresa do período de estiagem, envolvendo um mix menor de produtos, porém com grandes quantidades demandadas. Com um menor número de produtos, o número de variáveis do modelo se reduz. Resolvendo-se o modelo no software GAMS/ CPLEX, também se obteve uma solução melhor do que a praticada pela empresa, gerada em menos de 20 minutos de processamento e com gap de no máximo 7,67\%.

\section{Conclusões e perspectivas para pes- quisa futura}

No problema de dimensionamento e seqüenciamento de lotes na indústria de rações para nutrição animal, o objetivo é encontrar um programa de produção que atenda à demanda sem atrasos, otimizando a utilização dos recursos disponíveis. Na prática este problema é resolvido em duas etapas. O dimensionamento dos lotes é feito pela área de PCP, enquanto que o seqüenciamento é uma atividade transferida ao chão-de-fábrica. Tratar estes problemas de forma independente gera dificuldades para tornar a produção flexível às mudanças do mercado e para obter soluções (para os tamanhos e seqüência de lotes) viáveis do ponto de vista da capacidade disponível e do atendimento dos prazos de entrega. Por exemplo, os tamanhos de lote dimensionados pelo PCP podem ser inviáveis para a produção no chão-de-fábrica, pois os tempos de preparação são dependentes da sequiência e podem comprometer a capacidade disponível. Desta forma, um dos desafios do PCP é coordenar de forma eficaz estas decisões.

A abordagem proposta neste trabalho trata o problema de forma integrada, propondo um modelo de programação linear inteira mista para representar as decisões envolvidas e resolvendo-o no software GAMS/CPLEX, utilizando diferentes estratégias para reduzir os tempos computacionais. Experimentos limitados realizados com dados reais mostram que esta abordagem é capaz de gerar resultados melhores do que os utilizados pela empresa. Desta forma, o modelo parece ser apropriado para apoiar as decisões de dimensionamento e seqüenciamento de lotes na indústria rações para nutrição animal. Um inconveniente desta abordagem é o esforço computacional requerido pelo solver CPLEX para resolver o modelo, requerendo ordem de horas de um microcomputador.

Uma perspectiva importante para pesquisa futura é estudar e desenvolver métodos de solução (exatos e aproximados) alternativos para tratar o modelo, que garantam encontrar boas soluções em pouco tempo computacional (p.e., ordem de minutos). Tais métodos podem combinar técnicas de decomposição do modelo, técnicas de relaxação de restrições, procedimentos de relaxação e fixação de variáveis (relax-and-fix heuristics), além de heurísticas construtivas, buscas locais e metaheurísticas. Devido às incertezas em relação à demanda, uma aplicação mais efetiva da abordagem proposta também pode ser alcançada com a utilização do conceito de horizonte rolante.

\section{Agradecimentos}

Os autores agradecem aos revisores anônimos pelos úteis comentários e sugestões. Esta pesquisa contou com apoio da FAPESP (processo 02/06104-8) e CNPq (processo 522973/95-4). 
ALLAHVERDI, A.; GUPTA, J. N. D.; ALDOWAISAN, T. A Review of Scheduling Research Involving Setup Considerations. Omega International Journal of Management Science, v. 27, n. 2, p. 219-239, 1999.

ASSOCIAÇÃO NACIONAL DOS FABRICANTES DE ALIMENTOS PARA ANIMAIS. (ANFAL). Disponível em: <http://www.anfal.org.br>. Acesso em: 07 fevereiro 2003.

ARAÚJO, S. A.; ARENALES, M. N. Problema de Dimensionamento de Lotes Monoestágio com Restrição de Capacidade: Modelagem, Método de Resolução e Resultados Computacionais. Pesquisa Operacional, v. 23, n. 3, p. 403-420, 2003.

ARAUJO, S. A.; ARENALES, M. N.; CLARK, A. R. Dimensionamento de lotes e programação do forno numa fundição de pequeno porte. Gestão \& Produção, v. 11, n. 2, p. 165-176, 2004.

ASKIN, R.; STANDRIDGE, C. Modeling and analysis of manufacturing systems. New York: Wiley \& Sons, 1993.

BROOKE, A.; KENDRICK, D.; MEERAUS, A. GAMS: a user's guide (release 2.25). San Francisco: The Scientific Press, 1992.

CLARK, A. R.; CLARK, S. J. Rolling-horizon lot-sizing when set-up times are sequence-dependent. International Journal of Production Research, v. 38, n. 10, p. 2287-2307, 2000.

CLARK, A. R. Optimization Approximations for Capacity Constrained Material Requirement Planning: Internal Research Report. MS-20020-2. Bristol: University of the West of England, 2003.

DREXL, A.; HAASE, K. Proportional Lot sizing and Scheduling. International Journal of Production Economics, v. 40, n. 1, p. 73-87, 1995.

DREXL, A.; KIMMS, A. Lot sizing and scheduling: survey and extensions. European Journal of Operational Research, v. 99, n. 2, p. 221-235, 1997.

FLEISCHMANN, B. The discrete lot-sizing and scheduling problem with sequence-dependent setup-costs. European Journal of Operational Research, v. 75, n. 2, p. 395-404, 1994.

FLEISCHMANN, B.; MEYR, H. The general lot sizing and scheduling problem. OR Spektrum, v. 19 n. 1, p. 11-21, 1997.

GERSHWIN, S. Manufacturing systems engineering. New Jersey: Prentice Hall, 1994.
GRAHAM, E. L. et al. Optimization and approximation in deterministic sequencing and scheduling: a survey. Annals of Discrete Mathematics, v. 5, n. 2, p. 287-326, 1979.

GRAVES, S. C., RINNOOY KAN, A. H. G., ZIPKIN, P. H. Logistics of Production and Inventory. Handbook in operations research and management science, v. 4. Amsterdam North-Holland, 1993.

HAASE, K. Capacitated Lot-Sizing with Sequence Dependent Setup Costs. OR Spectrum, v. 18, n. 2, p. 51-59, 1996.

HAASE, K.; KIMMS, A. Lot sizing and scheduling with sequence-dependent setup costs and times and efficient rescheduling opportunities. International Journal of Production Economics, v. 66, n. 2, p. 159-169, 2000.

HAX, A.; CANDEA, D. Production and inventory management. New Jersey: Prentice-Hall; Englewood Cliffs, 1984.

JOHNSON, L. A.; MONTGOMERY, D. C. Operations research in production planning, scheduling and inventory control. New York: Wiley, 1974.

KARIMI, B. ;GHOMI, S. M. T. F; WILSON, J. M. The capacitated lot sizing problem: a review of models and algorithms. Omega International Journal of Management Science, v. 31, n. 5, p. 365-378, 2003.

LAGUNA, M. A. Heuristic for Production Scheduling and Inventory Control in the presence of SequenceDependent Setup Times. Internal Research Report. University of Colorado. 1999.

LAWLER, E.L. et al. Sequencing and scheduling: Algorithms and complexity. In: S.C. Graves, A.H.G. Rinnooy Kan and P.H. Zipkin, [editors]. Logistics of Production and Inventory. Handbooks in Operations Research and Management Science, North-Holland, 445-522, 1993.

LUCHE, J. R.; MORABITO, R. Otimização na programação da produção de grãos eletrofundidos: um estudo de caso. Gestão \& Produção, v. 12, n. 1, p. 135-149, 2005.

MAES, J; van WASSENHOVE, L. N. Multi-item single-level capacitated dynamic lot-sizing heuristics: a general review. Journal of the Operational Research Society, v. 39, p. 991-1004, 1988.

MEYR, H. Simultaneous lot sizing and scheduling by combining local search whit dual reoptimization. European Journal of Operational Research, v. 120, p. 311-326, 2000 . 
Simultaneous lot sizing and scheduling on parallel machines. European Journal of Operational Research, v. 139, p. 277-292, 2002.

NAHMIAS, S. Production and operations analysis. Local: Irwin, Homewood, IL, 1995.

POTTS C.; KOVALYOV M. Y. Scheduling with batching: a review. European Journal of Operational Research, v. 120, n. 2, p. 228-49, 2000.

RANGEL, S.; FERREIRA, D. Um modelo de dimensionamento de lotes para uma fábrica de refrigerantes. Tema (Tendências Em Matemática Aplicada e Computacional). São José do Rio Preto, SP: v. 4, n. 2, p. 237-246, 2003.

SALOMON, M. et al. Solving the discrete lotsizing and scheduling problem with sequence dependent set-up costs and set-up times using th Travelling Salesman Problem with time windows. European Journal of Operational Research, v. 100, n. 3, p. 494-513, 1997.

SINDICATO NACIONAL DA INDÚSTRIA DE ALIMENTAÇÃO ANIMAL (SINDIRAÇÕES). Perfil 2002, Posicionamento da Indústria de Alimentação Animal. Disponível em: <http://www.sindiracoes.org.br>. Acesso em: 07 fevereiro 2003.
STAGGEMEIER, A. T.; CLARK, A. R. A survey of lot-sizing and scheduling models. In: SIMPÓSIO BRASILEIRO DE PESQUISA OPERACIONAL, 33, 2001. Anais... 2001.

TOLEDO, C. F. M.; FRANÇA, P. M.; MORABITO, R. Proposta de um modelo conjunto de programação da produção e dimensionamento de lotes aplicado a uma indústria de bebidas. In: Encontro Nacional de Engenharia da Produção, 22, 2002, Curitiba-PR, Anais... 2002.

TOSO, E. Otimização do problema integrado de dimensionamento de lotes e programação da produção: Estudo de caso na indústria de rações. 2003. Dissertação (Mestrado em Engenharia de Produção). Programa de Pós-graduação em Engenharia de Produção. Universidade Federal de São Carlos. São Carlos, 2003.

TRIGEIRO, W. W.; THOMAS, L. J.; Mc CLAIN J. O. Capacitated lot sizing with setup times. Management Science, v. 35, n. 3, p. 353-366. 1989.

WILLIAMS, P. Model building in mathematical programming. New York: Wiley \& Sons, 1993.

WINSTON, W. Operations Research: Applications and algorithms. Boston, PWS-Kent, 1991.

\title{
OPTIMIZATION IN PRODUCTION LOT SIZING AND SEQUENCING: CASE STUDY OF AN ANIMAL FEED PLAN
}

\begin{abstract}
This paper proposes an approach to optimize the problem of integrated production lot sizing and sequencing in an animal feed plant. The problem consists of deciding how much of each feed to produce in each period, considering lot sequencing, so as to meet the demand while minimizing production and inventory costs. One of the major difficulties of production scheduling in this plant is to coordinate these decisions, since setup times are highly dependent on lot sequencing. The problem is modeled by mixed integer linear programming and is solved using the modeling language GAMS/CPLEX. Numerical experiments carried out with real data indicate that this approach can produce better results than those used by the plant.
\end{abstract}

Keywords: production lot sizing, lot sequencing, sequence-dependent setup time, animal feed. 